\title{
Aplicativos de monitoramento do ciclo menstrual e da gravidez: corpo, gênero, * saúde e tecnologias da informação
}

\author{
Gabriela Cabral Paletta** \\ Marina Fisher Nucci*** \\ Daniela Tonelli Manica****
}

\section{Resumo}

Neste artigo discutimos as relações entre corpo, saúde, tecnologias e gênero, a partir da análise de aplicativos de monitoramento de ciclos menstruais e da gravidez. Nosso interesse central é analisar, da perspectiva de gênero, que corpos se constituem a partir das interfaces dos aplicativos, e que tipos de dados são produzidos nesses ambientes. Articuladas aos ativismos feministas ligados à tecnologia, propomos uma análise desses aplicativos que tratam da saúde reprodutiva feminina, procurando situá-los no contexto da ampliação das tecnologias da informação ligadas à saúde e ao monitoramento dos corpos (Lupton, 2014).

Palavras-chave: Aplicativo, Ciclo Menstrual, Gravidez, Gênero, Antropologia da Ciência e da Tecnologia.

* Recebido em 01 de outubro de 2019, aceito em 10 de junho de 2020.

** Mestre, PPGSA, IFCS, UFRJ, Rio de Janeiro, RJ, Brasil. gabrielapaletta@gmail.com / https://orcid.org/0000-0001-6604-5891

*** Pesquisadora de Pós-doutorado, com bolsa Faperj, do Instituto de Medicina Social - IMS/UERJ, Rio de Janeiro, RJ, Brasil. marinanucci@gmail.com / https://orcid.org/0000-0003-3465-9201

**** Pesquisadora do Laboratório de Estudos Avançados em Jornalismo/Núcleo de Desenvolvimento da Criatividade, Unicamp, Campinas, SP, Brasil. dtmanica@unicamp.br / https://orcid.org/0000-0001-8014-9996 
Apps for Monitoring Menstrual Cycles and Pregnancy: Body, gender, health and information technologies

\begin{abstract}
:
In this article, we discuss the relations between body, health, technologies and gender, based on an analysis of apps for monitoring menstrual cycles and pregnancy. Our central goal is to analyze, from a gender perspective, what bodies are constituted by the interfaces of these apps, and what types of data are produced in these environments. Articulated with feminist activisms concerning technologies, we propose an analysis of apps that address female reproductive health, in an effort to situate them in the context of expansion of information technologies applied to health and the monitoring of bodies (Lupton, 2014).
\end{abstract}

Keywords: Apps, Menstrual Cycle, Pregnancy, Gender, Anthropology of Science and Technology. 
Este texto é baseado em uma pesquisa sobre aplicativos móveis que monitoram o sistema reprodutivo em corpos cisfemininos, mais especificamente, que acompanham e monitoram a gravidez e o ciclo menstrual. Nossa análise concentra-se em descrever diferentes interfaces envolvidas no processo, bem como discutir questões relacionadas à normatividade de gênero, vigilância e produção de dados de saúde. Examinando alguns dos emaranhamentos entre corpos, saúde, tecnologias e gênero presentes nos aplicativos de ciclo menstrual e gravidez, trazemos algumas perguntas: Quais tipos de corpos são representados nessas interfaces? Quais tipos de dados estão sendo produzidos por esses dispositivos?

Trazemos os resultados de uma análise sobre os aplicativos de monitoramento de ciclo menstrual (Paletta, 2019), correlacionada a um estudo sobre aplicativos de gravidez. Foram escolhidos para esta análise quatro aplicativos disponíveis em português e gratuitos, sendo dois de gravidez e dois de ciclo menstrual entre os mais baixados das Google Play Store e da App Store da Apple. Para os primeiros, foram eleitos "Gravidez+", que até agosto de 2018 contava com mais de 10.000 downloads na Apple e mais de 10.000.000 no Android, e "Minha gravidez e meu bebê hoje (BabyCenter)", com quase 5.000 downloads na Apple e mais de 10.000.000 no Android. Já para os de menstruação, selecionamos o "Calendário Menstrual" e o "Clue Calendário do ciclo menstrual e ovulação", com mais de 50 milhões e 10 milhões de downloads respectivamente.

Os aplicativos de gravidez promovem um acompanhamento semanal do andamento da gestação, com indicações das transformações corporais previstas para as gestantes naquela etapa, e apresentação de inúmeras imagens fetais estilizadas, simulações 3D de fetos dentro da barriga, além de recursos que dimensionam o tamanho do feto naquela semana gestacional específica. Já os aplicativos de monitoramento menstrual, ou menstruapps, representam uma variação dentre as técnicas que sempre estiveram presentes para registrar as variações do "ciclo menstrual", como anotações em agendas, calendários, observação 
das fases da lua, entre outras. De maneiras sutilmente diferentes, mas com implicações radicalmente importantes, esses aplicativos oferecem ferramentas para registrar informações a respeito do ciclo menstrual, como bloco de notas, emoticons que representam uma enorme variedade de humores e sintomas (físicos, emocionais, sociais e sexuais), gráficos da variação de peso e da temperatura basal, notificações sobre as próximas menstruações e/ou período fértil.

\section{Corpo, Gênero, Saúde e Tecnologias da Informação}

Tomamos uma perspectiva crítica sobre as relações entre corpos, códigos e informações. Com o irônico mito do ciborgue, Haraway (2009) formulou uma maneira interessante de pensar as codificações e informações que baseiam a compreensão de corpos nas sociedades contemporâneas. Releituras desses insights atualizam as tecnopolíticas de gênero atuais, articuladas pela biomedicina, as indústrias farmacêutica $e$ pornográfica $e$ as tecnologias digitais (Preciado, 2018). Dadas as atuais ameaças $e$ retrocessos aos direitos das mulheres no Brasil, especialmente no que se refere aos direitos sexuais e reprodutivos, também alinhamos nossa postura crítica ao ativismo das tecnologias feministas ao formular nossa análise desses aplicativos. De acordo com ativistas preocupadas com tecnopolíticas sensíveis às questóes de gênero, as tecnologias de informação relacionadas à saúde são uma forma de produzir dados a partir de um autorastreamento (Lupton, 2014), que possibilitam o monitoramento corporal.

Em "O Manifesto Ciborgue", Donna Haraway (2009), propóe a metáfora do ciborgue como um organismo cibernético, híbrido de máquina e organismo e misto de ficção e realidade. Ele vive em mundos ambíguos, $e$ transita entre o natural $e$ o fabricado. Haraway argumenta em favor do ciborgue como uma ficção que mapeava a realidade social e corporal na década de 1980. O ciborgue é, ao mesmo tempo, texto, máquina, metáfora e corpo, integrado na prática como comunicação. 
Preciado (2014), por sua vez, apresenta a ideia de que a relação promíscua entre tecnologias e corpos é uma chave de análise importante para se escapar ao debate essencialismo/construtivismo sobre o corpo. Trata-se, então, de estudar de que modos específicos a tecnologia "incorpora", "se faz corpo". Ao falar, por exemplo, do processo de aprender a datilografar como uma forma de mimetizar a escrita que prescinde da visão (uma "escrita cega", fruto de uma tecnologia criada para a escrita de pessoas que não enxergam), Preciado extrapola esse processo para pensar as relações entre corpo e técnica. Uma vez que a prótese está dotada de uma sensibilidade fantasmática, que está incorporada à memória do corpo e suas ações, o modelo mecânico que estabeleceria esta prótese como um simples "instrumento" é rompido.

Para Preciado (2018), o regime farmacopornográfico é um regime pós-industrial, global e midiático que enquadra corpos $e$ técnicas em uma nova governamentalidade. $\mathrm{O}$ termo se refere aos processos de governo biomolecular (fármaco-) e semiótico-técnico (-pornô) da subjetividade sexual, cujas raízes estão fincadas na sociedade científica e colonial do século XIX. A nossa economia mundial hoje depende, pelo olhar deste autor, da produção $e$ circulação interconectada de toneladas de esteroides sintéticos $e$ órgãos, fluidos e células tecnicamente modificados (tecnoesperma, tecnossangue, tecnoóvulo); de um fluxo de imagens pornográficas, da elaboração de novos psicotrópicos sintéticos, e do fluxo de sinais e circuitos digitais de informação. $\mathrm{E}$ o sucesso da indústria tecnocientífica contemporânea está na transformação da depressão em Prozac, ereção em Viagra, masculinidade em testosterona, a escolha entre a Pílula ou a maternidade (Preciado, 2018). O controle, a produção $e$ intensificação dos afetos narcossexuais tornaram-se o modelo para todas as outras formas de produção de modo a infiltrar e dominar todo o fluxo de capitais, indo da biotecnologia agrária até a indústria high-tech da comunicação. 
Neste período de gestão técnica do corpo, a indústria farmacopornográfica sintetiza e define um modo especifico de produção e consumo, uma temporalização masturbatória da vida, uma estética virtual e alucinógena do objeto vivo, uma arquitetura que transforma o espaço interior em exterioridade e a cidade em interioridade e junkspace por meio de dispositivos de autovigilância imediata e difusão ultrarrápida de informação, um modo contínuo de desejar e resistir, de consumir e destruir, de evoluir e se extinguir (Preciado, 2018:43-44).

Nesse contexto, e tomando como base uma perspectiva feminista neo-materialista (Lupton, 2019), cabe pensar as diferenças e proposições que estão sendo articuladas com os aplicativos de monitoramento de ciclo menstrual e de gravidez, à medida em que há um novo arranjo para mediar os componentes informacionais $e$ materiais que permitem progressivamente adquirir um corpo. De que maneira os aplicativos de ciclo menstrual e gravidez, ao articular telefones celulares, informações digitais, sangue, embrióes, fetos, e sensações, performam (cf. Mol, 2002) corpos, experiências e técnicas?

Compreendemos estes aplicativos através de uma abordagem que vê as tecnologias digitais de saúde como artefatos sociais, culturais, materiais e envolvimentos corporais (Lupton, 2014) com implicações políticas que constituem e formatam os "ciclos menstruais" ou a "gravidez", delimitando as possibilidades de definição e compreensão do que eles são. Segundo Deborah Lupton (2014), estas tecnologias são participantes ativos que moldam corpos humanos e pessoas como parte de redes heterogêneas, criando novas práticas e conhecimentos. Ela ainda considera que parte desse movimento em direção à introdução de dispositivos digitais e aplicativos associados, plataformas e sites, que permitem às pessoas monitorar $e$ medir suas atividades $e$ funções corporais, envolve a transformação dessas atividades e funções em dados digitais quantificáveis. Essas práticas também são chamadas de "autorastreamento" ou "quantificação do eu". 
Lupton (2016) traz ainda a importância da dimensão da privacidade, segurança dos dados e a venda de big data. Sabe-se, por exemplo, que muitos desenvolvedores de aplicativos armazenam seus dados em nuvens, e nem todos os identificadores de nome são removidos dos dados enviados pelos usuários - este acordo deveria estar estabelecido e selado pela aceitação das políticas de privacidade. Uma vez que os dados foram enviados e arquivados, pode ser muito difícil apagá-los. Questões de privacidade são uma preocupação em relação a qualquer uso de dados das interações dos usuários com as tecnologias digitais, mas nada parece tão grave quanto a circulação $e$ acumulação de dados extremamente pessoais, como dados de sexualidade $e$ reprodução.

Outras referências importantes para pensar processos contemporâneos que envolvem a recodificação de aspectos de saúde e de gestão dos corpos em sistemas de controle $e$ informação configuram um amplo campo de discussões sobre a governamentalidade $e$ a vida em sociedades tecnologicamente mediadas (Kanashiro, 2011; Boulos et al. 2014; Sanders, 2016; Van Djick, Poell, 2016; Barassi, 2017; Elias, Gill, 2017).

Os aplicativos de monitoramento do corpo e da saúde são serviços que funcionam através da acumulação e da gerência dos dados coletados. Segundo Lupton (2016), automonitoramento é um conjunto de práticas nas quais as pessoas coletam intencional e propositalmente informações sobre si mesmas, com o fim de analisá-las e considerá-las na conduta de suas vidas. Desde o advento da computação $e$ da possibilidade de processamento digital dessas informações, o automonitoramento foi transformado em grandes práticas interconectadas, com implicações sociais, culturais e políticas distintas e significativas.

O auto-rastreamento, sinônimo para o automonitoramento, pode ser descrito também como uma prática biométrica quando se dedica à medição e monitoramento de características únicas de corpos humanos. Dados e práticas biométricas têm sido usados cada vez mais na inclusão, exclusão e na manutenção de fronteiras, na governamentalidade de pessoas, corpos e seus 
fluxos e trânsitos em sistemas de informação e controle (Kanashiro, 2011; Lupton, 2016).

A partir do que propõem essas autoras, podemos pensar as práticas de automonitoramento como parte dos enquadramentos contemporâneos para compreender, controlar, gerenciar, regular, executar e expressar corpos e seus agenciamentos. Mas, para além dos propósitos mais diretamente ligados ao Estado $e$ à governamentalidade, essas técnicas que envolvem automonitoramento mobilizam também a "vontade de saber" (Foucault, 1976) das pessoas sobre seus próprios corpos $e$ processos. Esses desejos colaboram para a adesão das usuárias aos aplicativos que monitoram fertilidade e reprodução.

Pesquisando sobre aplicativos de automonitoramento voltados para sexo e reprodução, Lupton (2015) encontrou que a vigilância "autoimposta" se torna mais agradável e divertida quando um objetivo (como a (não) concepção, por exemplo) está em jogo. Alguns autores têm caracterizado isso como uma lógica de "gamificação", que visa promover o engajamento constante $e$ efetivo dos usuários aos aplicativos e sistemas que concentram informação digital (Lister et al., 2014; Sacramento, Wanick, 2017). A criação desse tipo de objetivo faz toda a diferença na adesão da usuária aos aplicativos.

A cultura de "autorastreamento" (Lupton, 2016) está baseada na ideia de que o surgimento destes dispositivos digitais e móveis facilitaria o automonitoramento, com a geração de dados pessoais quantificados. Existe a crença de que estes dados (e particularmente dados quantificados ou quantificáveis) são um caminho para o autoconhecimento $e$, portanto, são entidades poderosas; de que é importante não apenas coletar dados quantificados sobre si mesmo, mas analisá-los para encontrar padrões que eles revelam; que os dados quantificáveis são mais neutros, confiáveis e objetivos do que os dados qualitativos, que são vistos como intuitivos, emocionais e/ou subjetivos; que dados de automonitoramento podem fornecer informações mais interessantes do que os insights que as pessoas recebem de seus próprios sentidos, revelando padrões ou correlações anteriormente 
ocultas e cujo processamento depende de cálculos algorítmicos e recursos informacionais; que os dados de autorastreamento podem ser fenômenos motivacionais, inspirando a ação ao entrar em um ciclo de feedback, e, finalmente, que os dados sobre os indivíduos são emblemáticos de seu "verdadeiro eu".

O "eu-quantificado", conceito elaborado por Gary Wolf $e$ Kevin Kelly (apud Lupton, 2016), refere-se ao uso crescente de números como um meio de monitorar e medir elementos da vida cotidiana e da corporificação, podendo ser interpretado mais amplamente como um ethos e um aparato de práticas que ganharam força nesta era de dispositivos digitais móveis e vestíveis, com ambientes físicos cada vez mais saturados por sensores.

Dentro das práticas de automonitoramento, o autoconhecimento, a compreensão detalhada do corpo e de suas funções seriam alcançadas principalmente por meio desses números. Lupton (2016) traz a dimensão de como é evidente, em muitos relatos de auto-rastreamento na cultura popular, assim como na literatura médica e de saúde pública, que os dados quantitativos são representados como formas objetivas de informação, em contraponto às informações advindas das próprias experiências subjetivas das pessoas sobre suas sensações corporais e ritmos. A produção de dados quantitativos via tecnologias digitais é retratada como contribuindo para sua neutralidade objetiva, supostamente removida das ações subjetivas dos seres humanos.

Os dados digitalizados exercem uma autoridade especial sobre outras fontes de informação sobre si mesmo ou sobre os outros, porque são vistos como mais objetivos, detalhados, "do momento" e capazes de integrar informações de várias fontes diferentes. Ao contrário da informação supostamente subjetiva que as pessoas recebem de seus sentidos e através de observações, os dados digitais carregam consigo uma aura de autoridade científica (Lupton, 2016:55, tradução livre). 
Segundo Deborah Lupton (2016), existem vários riscos na segurança de dados associados a um grande número de aplicativos e dispositivos de automonitoramento, sobretudo no que diz respeito ao fácil acesso (através de venda ou não) aos dados pessoais por terceiros, para ganhos comerciais. E se algum possível empregador soubesse, assim como sabe o menstruapp, que uma empregada está tentando engravidar, por exemplo? Teria efeitos numa possível contratação de emprego? Agora, e se o mercado virtual inteiro soubesse qual fase do ciclo ou do mês ela está mais vulnerável a gastar mais, agir impulsivamente? E se as seguradoras e planos privados de saúde passarem a recompensar com descontos clientes que adotam um determinado estilo de vida "mais saudável" ou que são mais cautelosos no trânsito? Como estar ciente de todos os usos destes dados? Como distanciar esta discussão das discussões de gênero?

Apresentaremos a seguir o esforço analítico que fundamenta a proposta desse artigo, que envolve descrever os aplicativos $e$ suas funcionalidades, com o objetivo de delinear as corporalidades que se constituem na convergência entre as informações disponibilizadas pelas usuárias, e processadas pelos aplicativos. Esses aplicativos foram baixados pelas autoras do artigo, e suas interfaces analisadas de acordo com o uso sugerido na instalação.

Descreveremos, inicialmente, os aplicativos de ciclo menstrual e, na sequência, os de gravidez, tendo como eixos de análise as seguintes temáticas: informações sobre o contexto de produção do app; recursos de (in)segurança da informação; formatação da tecnologia do aplicativo (tipos de dados que são registráveis ou que circulam através deles); vigilância, normatividade e (auto)monitoramento; $e$ os sentidos de gênero $e$ sexualidade que se performam nos aplicativos.

\section{Temporalidades e Regulações: Os Menstruapps}

Quando procuramos por palavras-chave como "menstruação", "ciclo menstrual" e "calendário menstrual" na 
App Store da Apple e na Google Play Store aparecem mais de mil resultados de aplicativos relacionados, pagos e gratuitos (Moglia et al, 2016). Entre os aplicativos gratuitos mais instalados estão dois menstruapps que serão alvo de nossa análise: o "Calendário Menstrual" da empresa chinesa Simple Design Ltd., lançado em março de 2012; e o "Clue Calendário do ciclo menstrual e ovulação" desenvolvido pela alemã BioWink $\mathrm{GmbH}$, lançado em outubro de 2014, com mais de 50 milhões e 10 milhões de downloads respectivamente.

Dentre suas diversas finalidades e funções, esses aplicativos têm em comum alguns objetivos, como o de estimar datas prováveis de ovulação e de menstruação. Eles se pretendem eficazes e cientificamente fundamentados tanto para fins contraceptivos quanto para quem deseja engravidar, e cada aplicativo se propõe a atingir esses objetivos de maneiras distintas.

Para chegar à tela inicial de ambos os aplicativos é necessário responder a algumas perguntas preliminares como: "Qual é a duração da sua menstruação?", "Qual é a duração do seu ciclo?", "A data de início da sua menstruação?". Sem responder essas perguntas, não se tem acesso aos aplicativos, só sendo possível navegar por eles completamente após fornecer essas informações. Como veremos a seguir, essas informações são efetivamente valiosas para o mercado da produção de dados digitais, sendo esta uma das condições para que os aplicativos sejam gratuitos (Felizi E Varon, S/D). Essas informações também servem como um primeiro input, se fazendo possível, quando não necessário, que a usuária opte por um "objetivo de uso" para que o algoritmo do aplicativo passe a funcionar, dentre eles: evitar gravidez, engravidar, ou conectar-se ao ciclo de outra pessoa. 
Figura 1: Tela inicial do Calendário Menstrual

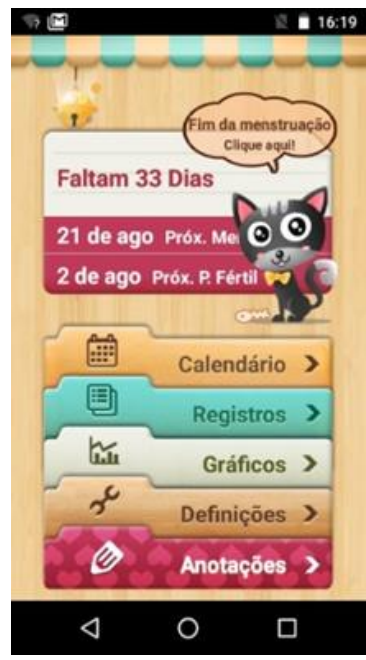

Os ícones que representam os aplicativos se propõem "discretos" (Clue é representado por uma mandala e o Calendário Menstrual por uma flor), evitando uma conexão explícita do app com imagens relacionadas ao sangue menstrual.

- As interfaces e a construção do corpo cíclico

Como ferramenta de leitura do(s) ciclo(s), os aplicativos em questão utilizam alguns métodos que são velhos conhecidos nas práticas de monitoramento menstrual, como o "calendário" e a "mandala lunar". O "calendário" consiste na sinalização das datas de menstruação em um calendário gregoriano, é utilizado para acompanhamento do ciclo menstrual e ficou muito conhecido por fundamentar os cálculos do método da "Tabelinha". Tanto o Calendário Menstrual quanto o Clue organizam, também, em suas interfaces digitais, um calendário composto por cores e ícones que representam os sintomas e condições escolhidos cotidianamente pela usuária. 
Figura 2: Calendários presentes na interface do Calendário Menstrual à esquerda, e do Clue, à direita.

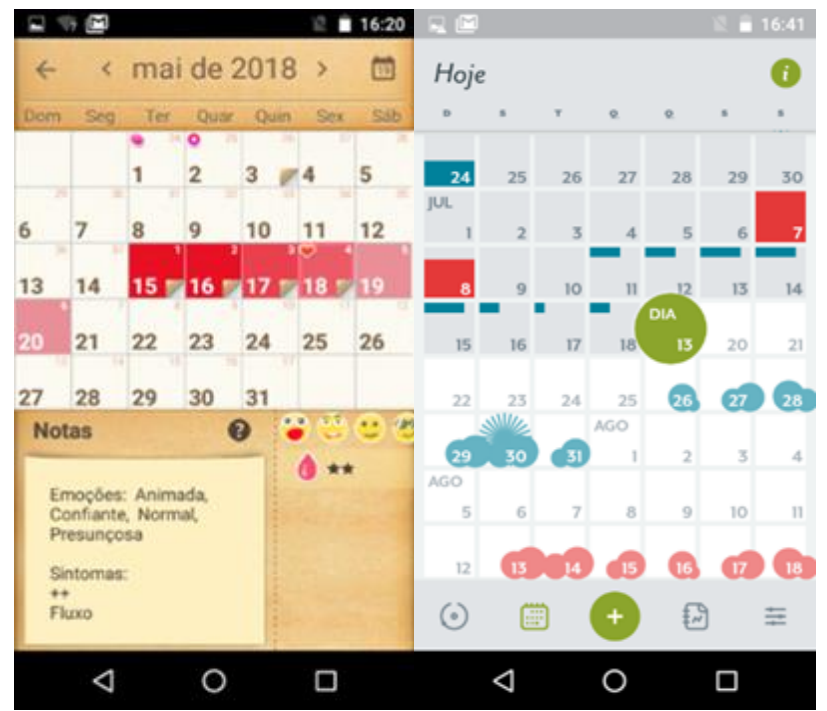

O aplicativo Clue também oferece um gráfico em mandala que retoma a antiga prática das mandalas lunares, apesar de ser um dispositivo completamente diferente. A tecnologia da Mandala Lunar é um instrumento que "permite comparar as descobertas de cada mês e organizá-las de modo a obter um guia de seu próprio ciclo menstrual" (Gray, 2017:129). Ela consiste no desenho de uma circunferência, dividida pela quantidade de dias de um ciclo lunar, e expressa os registros de informações sobre emoções, saúde, sexualidade, energia criativa, as mudanças de fase da Lua e o que mais seja relevante para quem está fazendo o registro. Enquanto tecnologia, a Mandala Lunar na maioria das vezes tem o gráfico reproduzido em papel e deve ser preenchido ao longo do mês através de elementos diversos que não estão dados a priori, como lápis de cor, giz de cera, caneta, lápis, palavras, desenhos, rabiscos... Neste sentido, ela produz agenciamentos, objetivos $e$ subjetivos, quando implica mulheres na confecção de uma expressividade cíclica. 
A versão gráfica da mandala no Clue vai ganhando cores relacionadas a categorias pré-determinadas à medida em que os dados vão sendo inseridos. Convocando uma rede de atores $e$ agências completamente diferente da Mandala Lunar, à luz de um recorte científico e da biomedicina, na mandala do Clue é possível encontrar uma estimativa de "Janela de Fertilidade" e de TPM, que são calculadas pela média dos dados fornecidos nos últimos 3 ciclos logo assim que uma nova menstruação é adicionada.

Figura 3: Gráfico em mandala do Clue

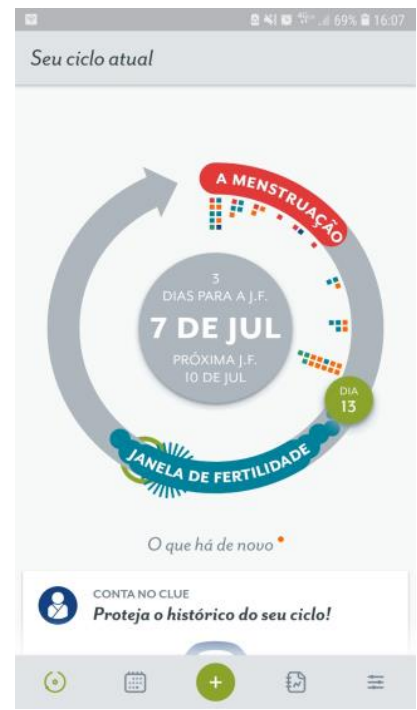

No Calendário Menstrual existe um espaço de notas, no qual a usuária pode escrever o que ela achar relevante a cada dia, dentre uma gama de mais de 64 emoções e uma lista de sintomas separados em seis categorias: "cabeça", "corpo", "colo do útero", "fluido", "abdômem" e "mental". 
Figura 4: Capturas de tela dos sintomas, emoções e variações de humor do Calendário Menstrual

Adicionar Sintoma

No Clue, por sua vez, existem 28 categorias de rastreamento, incluindo "menstruação", "cólicas", "emoções", "peso", "pele", "cabelo", "sono", "exercício", "energia", "desejos", entre outros. Estas categorias são, em geral, relacionadas a sintomas biopsicossociais, físicos, sangramento menstrual $e$ atividades sexuais. É preciso deslizar as categorias para os lados para navegar e marcar suas opções. Cada categoria possui 4 opções de marcação, por exemplo: o sangramento pode ser "leve", "médio", "intenso" ou "moderado"; as emoções disponíveis são "feliz", "sensível", "triste" e "TPM"; o desejo pode ser "doce", "salgado", "carboidrato" ou "chocolate". A próxima figura ilustra a distribuição das categorias em ícones no dispositivo. 
Figura 5: Exemplos de categorias e opções do Clue
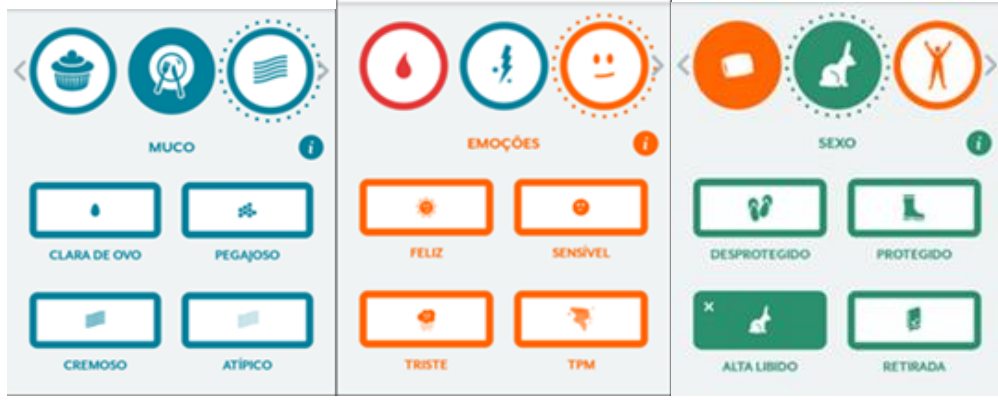

As informações que podem ser coletadas estão vinculadas a compreensões biomédicas do que é o "ciclo menstrual" e seu vínculo a um enquadramento ligado à reprodução. Assim, são monitoráveis a ovulação, fertilidade e práticas ligadas à contracepção, bem como a libido, relações sexuais e orgasmos. Sintomas ligados à "tensão pré-menstrual" (dores de cabeça, inchaços, dor nos seios, irritação ou depressão) também compõem o repertório.

Vinculando-se às técnicas de percepção da fertilidade (Klöppel, 2017), os aplicativos contêm ainda a opção de acompanhar o ciclo menstrual através de sintomas como a variação da textura da secreção vaginal, a variação de temperatura corporal basal (TCB) e de peso (estes últimos dois, representados por gráficos). Jane Knight (2016) divide estes métodos de percepção da fertilidade entre: 1) aqueles baseados na observação dos sintomas primários ao longo do ciclo (muco vaginal, temperatura basal e altura/densidade do cérvix); 2) os métodos baseados no calendário; e 3) os métodos baseados na tecnologia (que incluem testes de hormônio luteinizante na urina $e$ monitores de fertilidade).

$\mathrm{O}$ que os menstruapps oferecem como novidade é uma plataforma digital na qual se torna possível cruzar ao mesmo 
tempo todas estas maneiras de combinar indicadores. Em outras palavras, os aplicativos se baseiam em uma combinação de diferentes métodos de percepção da fertilidade. Entretanto, os aplicativos não cruzam estes dados automaticamente, fazendo do engajamento da usuária, que nutre os aplicativos com seus dados pessoais, um fator crucial para a eficácia da sua "inteligência artificial".

Como descreve Bruna Klöppel (2017), o período que é indicado como "fértil" se modifica, dependendo dos indicadores utilizados. Isso se deve porque, mesmo havendo certa estabilização em torno da quantidade de tempo que o óvulo pode sobreviver após a ovulação (24 horas) e da quantidade de dias que o espermatozóide conseguiria sobreviver no útero (sete dias no máximo), considera-se difícil precisar o momento exato da fecundação. Desta maneira, "diferentes indicadores podem apontar para diferentes momentos, fazendo com que o período fértil seja performado diferentemente" (Klöppel, 2017:38-39). Isso reforça a falta de acuidade e confiabilidade destes aplicativos, o que impede que sejam considerados métodos contraceptivos eficazes, pois isso implicaria a precisão na previsão da fertilidade.

\section{- Automonitoramento e gestão de informações}

No que diz respeito às "Políticas de Privacidade" do Calendário Menstrual, o documento é bem simplório e pouco informativo. $\mathrm{O}$ texto é disponibilizado somente em inglês, mesmo tendo sido o aplicativo traduzido para quarenta idiomas diferentes. Nele há informações básicas sobre os dados pessoais que os aplicativos coletam através de cookies em seu próprio site e nos fóruns de discussão, e sobre como são usadas as informações coletadas. A Simple Design "garante" que as informações pessoais identificáveis serão usadas apenas para entrar em contato com a usuária e/ou melhorar o serviço.

Já no caso do Clue, tanto os "Termos de Uso" quanto as "Políticas de Privacidade" estão disponíveis em português, e em outros 13 idiomas. O texto das "Política de Privacidade" do Clue é 
extenso e escrito de forma a se fazer entender. Vale ressaltar os seguintes pontos, que são assinalados nos termos de serviço: a usuária tem de ter 13 anos de idade para criar uma conta, e o serviço não foi concebido para substituir as medidas de contracepção e/ou conselho médico.

Figura 6: Captura de tela de parte do texto das Políticas de Privacidade do Clue

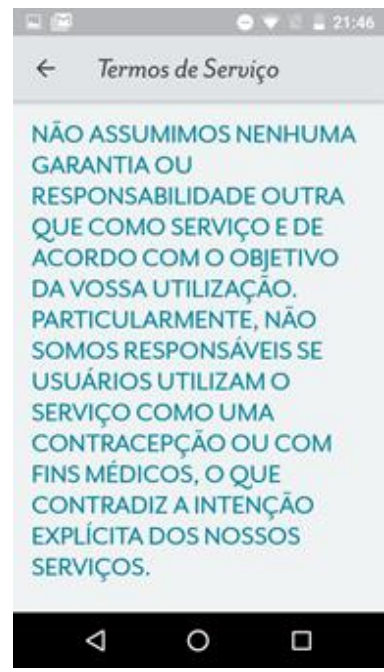

Tendo sua sede em Berlim, esta empresa lida com dados de acordo com as diretrizes legais exigidas na União Europeia. A respeito de suas Políticas de Privacidade, Clue estabelece como objetivos "fornecer a você um ótimo serviço" e "ajudar a aprimorar as pesquisas sobre a saúde da mulher em todo o mundo". A proposta de Ida Tin, fundadora do Clue, é disponibilizar dados anônimos para pesquisas de longo prazo ou de larga escala sobre saúde cíclica para pesquisadores acadêmicos e clínicos. Antes de serem oferecidos, os dados são "anonimizados" por meio da remoção de informações utilizadas para identificar quem os fornece.

Apesar da "segurança", no que se refere ao anonimato, que os termos oferecem à usuária em relação aos dados pessoais 
disponibilizados para acompanhar o próprio ciclo, o Clue acaba por ser bastante voraz na sua captura: este é um aplicativo que se insere no mercado incorporando à sua marca a tônica das discussões a respeito de homossexualidades, transexualidades, não-binariedade, anticapacitismo e se propõe alinhado a algumas críticas feministas contemporâneas, sobretudo no que tange ao uso do que a empresa chama de "linguagem inclusiva". Em texto publicado no site da empresa e enviados para os contatos de $e$ mail cadastrados, intitulado "Accessibility and gendered language at Clue" ("Linguagem de gênero inclusiva no Clue", em tradução livre), encontramos a seguinte definição de "Para quem é o app Clue?":

Sempre tentamos ser acessíveis e fáceis de entender sem nos referirmos ao gênero.

Em vez de criar conteúdo específico para determinadas personas de usuários ou projetar uma idéia abstrata de "mulher", o Clue foi feito para ser feliz, rápido de usar e ajudar na descoberta de informações precisas. Acreditamos que eles se aplicam a todos os milhões de usuários, independentemente do sexo.

Nas mais de 100 páginas de texto embasado cientificamente na versão em inglês da Clue - que aborda tópicos de saúde menstrual, fertilidade, condições médicas comuns, TPM / PME, sexo, seios, ovários, vaginas e tantos outros tópicos nunca referimos uma única vez para "mulheres" ou "mulheres". (Outros idiomas apresentam desafios únicos no que diz respeito ao idioma de gênero, mas também estamos trabalhando para melhorar isso.)

Fizemos isso como um esforço para ser preciso em relação aos nossos usuários, não como um esforço para ser "politicamente correto". Ao tomar decisões sobre o idioma que usamos, sentimos confiança de que a precisão é uma boa base sobre a qual construir. (Fonte: https://helloclue.com/articles/culture/accessibility-genderedlanguage-at-clue, último acesso em 31/05/2020, tradução livre). 
Em outro artigo do site intitulado "Desafiar a gramática e as noções de gênero", disponível em português, afirma-se:

\begin{abstract}
Algumas mulheres não têm menstruação $e$ algumas pessoas que menstruam não são mulheres. Essas pessoas podem ser homens trans, intersex, genderqueer ou adeptas de outros termos, como nonbinary.

Usar uma linguagem inclusiva de gênero é parte integrante do que fazemos no Clue, e não apenas em inglês. $O$ aplicativo Clue está disponível em 15 idiomas: dinamarquês, francês, alemão, hindi, italiano, japonês, coreano, polonês, português, russo, chinês simplificado, espanhol, chinês tradicional e turco, e esperamos adicionar mais idiomas em breve. (Fonte: https://helloclue.com/pt/artigos/cultura/desafiar-a-gramatica-e-asnocoes-de-genero, Último acesso em 31/05/2020).
\end{abstract}

Contudo, os dados produzidos através dele falam do emocional, da afetividade e do funcionamento libidinal da usuária e são postos, declaradamente, em circulação e negociação com empresas, pesquisadores, universidades e laboratórios. Além disso, o conteúdo do aplicativo não demonstra estar adaptado a especificidades da saúde cíclica da população trans, não-binária ou com deficiência física, se valendo de pautas enquanto trata delas de maneira homogeneizante.

O Clue performa uma coleta massiva de informações acerca dos mais diversos espectros das vidas das mulheres, que vão desde qualidade de sono, quantidade de exercícios físicos, qualidade da pele e cabelos, a como estão funcionando a digestão $e$ o intestino. Para além da questão da privacidade e do anonimato dessas informações, há uma acumulação de muitas informações bastante valiosas no mercado e nas novas maneiras de exploração econômica e mineração de dados (Parra, 2018).

Da perspectiva das relações e conexões com o repertório científico e biomédico sobre ciclo menstrual, o Calendário Menstrual não oferece quaisquer referências a respeito das informações disponíveis para consulta em sua interface. Já o 
aplicativo Clue, no que tange às referências mobilizadas para disponibilização das informações, oferece uma "Enciclopédia", na qual explicita em verbetes cada termo utilizado no aplicativo, acompanhado das respectivas referências.

Figura 7: Textos informativos das perguntas preliminares do Clue
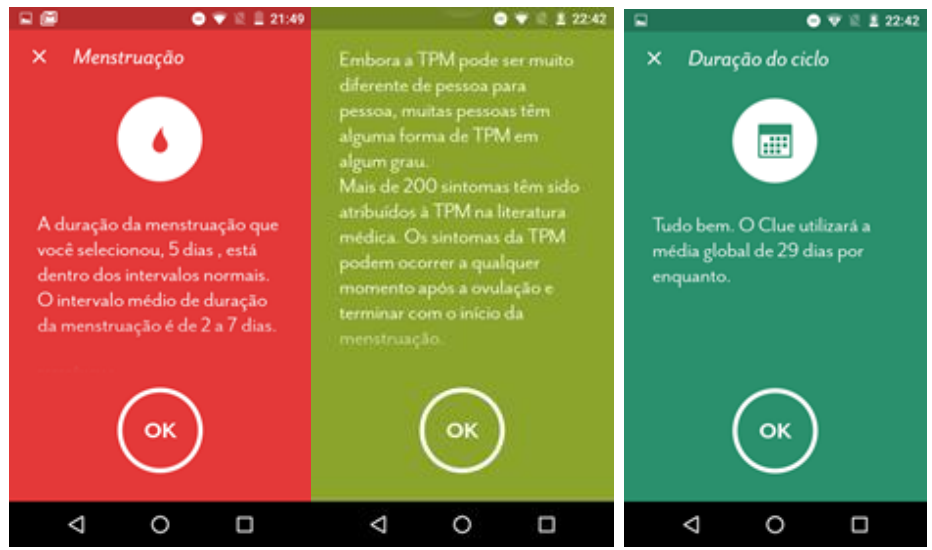

Outro recurso presente no cálculo dos menstruapps, que ajuda a cooptação do engajamento das usuárias é que em ambos aplicativos os cálculos são efetuados a partir das últimas três menstruações registradas. Caso o início de algum período não seja informado, podem acontecer duas coisas com as previsóes: ou o ciclo com a duração irregular é anulado do cálculo (como acontece com o Clue, por exemplo), ou então ele entra no cálculo de médias e a previsão fica prejudicada (como no Luna e no Calendário Menstrual). Ou seja, o preenchimento constante dos dados relativos ao ciclo é o que, supostamente, garante que o algoritmo funcione e obtenha um resultado próximo ao que foi prometido.

O corpo performado nestes aplicativos de automonitoramento, é sujeito $e$ produto de medição $e$ interpretação "científicas". Usar essas tecnologias, segundo Lupton (2015), incentiva as pessoas a pensarem sobre seus corpos através de números, como por exemplo: atividade sexual reduz-se ao 
"número" em que um certo tipo de relação sexual ocorre, a quantos "orgasmos" foram alcançados; uma "menstruação saudável" tem sangramento de 10 a $80 \mathrm{ml}$ de sangue por ciclo ao longo de cinco dias; qualidade de sono é medida pela quantidade de horas dormidas. Neste sentido, "transformar a sensação, comportamento e percepção carnais em números produzidos digitalmente torna-se uma maneira de dominar as incertezas, imprecisões e imprevistos do embodiment humano" (Lupton, 2016:53, tradução livre).

Figura 8: Botão para selecionar a opção de preservativos nas relações sexuais do Calendário Menstrual

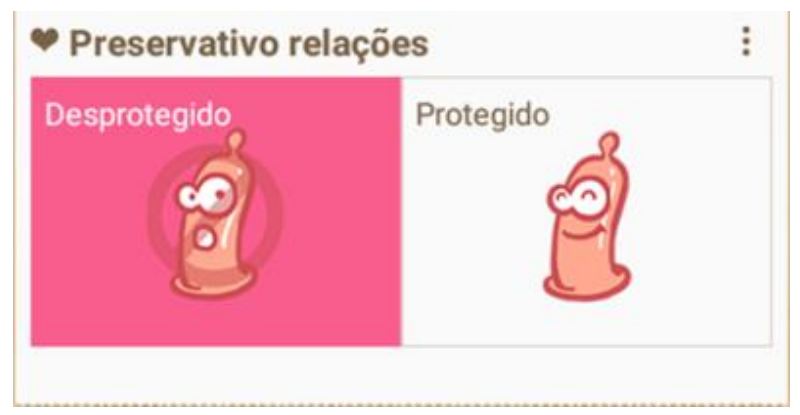

- Ciclicidade e fertilidade: sentidos de gênero nos aplicativos

Retomando Preciado (2018), gênero pode ser pensado como uma forma de tecnoecologia política, um programa operacional que desencadeia percepções sob a forma de afetos, desejos, ações, crenças e identidades. Este programa operacional está conectado a diversos atores, e entendemos que, como tecnologias farmacopornográficas, os menstruapps operam um destes vetores das tecnologias de gênero. Técnicas fotográficas, biotecnológicas, cirúrgicas, farmacológicas, cinematográficas ou cibernéticas constroem a materialidade dos sexos. Em outras palavras, a menstruação, o ciclo menstrual e suas práticas de gestão de cuidado configuram, nesses aplicativos, tecnologias de produção de gênero. 
A menstruação, a partir dos aplicativos, aparece como algo possivelmente debilitante, passível de medicalização e algo que se faz necessário controlar: é preciso saber quando começa, quando termina e os efeitos desses acontecimentos para a vida, o corpo, o humor $e$ as emoções das usuárias. Entendendo gênero como uma tecnologia material-discursiva, que existe na medida em que seus efeitos se tornam reais, as categorias "reprodução", "fertilidade" $e$ "menstruação" contribuem para a constituição de uma diferença de gênero corporificada, ao mesmo tempo em que delimitam determinados corpos como alvos privilegiados de intervenção $e$ controle.

Muitos dos sintomas e emoções presentes nos aplicativos estavam associados a uma noção geral de descompensação de humor, de variações de hormônios e de hábitos alimentares potencialmente irregulares, referentes aos pressupostos do que se espera no período pré-menstrual - como se alguma coisa (como a fertilização e a concepção, por exemplo) tivesse "dado errado", falhado. Diferenças no padrão esperado podem, também, compor os primeiros indícios e sintomas de uma gravidez.

Joana Varon e Natasha Felizi definem os aplicativos como "um espaço controlado, onde você registra informações íntimas e pode interagir com outras pessoas sobre o assunto, desde que seja no fórum/espaço apropriado" (Ribeiro, 2017). Longe de serem um espaço de possível politização e desenvolvimento da autonomia $e$ empoderamento, esses espaços pareceriam mais "banheiros cor de rosa e vigiados, cheios de mensagens heteronormativas $e$ propagandas de consumo que reforçam essa construção do gênero mulher".

Desta maneira, atingir um objetivo (como o de engravidar ou evitar a gravidez) dentro de uma trajetória de vida é simplesmente uma questão de aplicar o conhecimento de forma eficaz através da modulação de comportamento. A lógica que embasa o funcionamento do algoritmo pressupõe que, quando o conhecimento apropriado é obtido e aplicado, a maioria dos problemas e dificuldades pode ser resolvida. Qualquer sugestão de que as dificuldades de uma pessoa possam ser causadas por 
problemas biológicos intratáveis (uma predisposição genética para doenças, por exemplo), psíquicos ou até por questões de classe ou raça tende a ser desconsiderada por esse foco na gestão $e$ responsabilidade pessoal (Lupton, 2016). A superação de dificuldades torna-se firmemente posicionada como culpa do indivíduo privado e não de sua vantagem social e econômica relativa, fortalecendo toda uma lógica neoliberal, patriarcal, racista e heteronormativa.

\section{Gestações sob controle}

Para nossa análise sobre os aplicativos de celular para gravidez, selecionamos os dois mais baixados nas lojas dos sistemas operacionais Apple e Android: "Gravidez+" e "Minha gravidez e meu bebê hoje (BabyCenter)". Ambos os apps são gratuitos e estão disponíveis em português.

Ao serem iniciados pela primeira vez é solicitado um cadastro no qual, além de dados como nome, país e data de nascimento, deve-se incluir, em caso de gravidez, a data da última menstruação. A partir desta informação, os aplicativos calculam a data provável do parto e a semana em que a gravidez se encontra.

O aplicativo Gravidez+ é criado pela empresa Health \& Parenting Ltd. em parceria com a Philips Consumer Lifestyle CV, sediada nos Estados Unidos. Está disponível em dez idiomas diferentes. No caso da tradução para o português, porém, é possível perceber em alguns momentos que o conteúdo não foi propriamente adaptado para o contexto brasileiro. Já o aplicativo BabyCenter foi criado pela empresa BabyCenter L.L.C, também com sede nos Estados Unidos, e está disponível em seis idiomas diferentes e em nove versões. Além do app, há também um site na internet com o mesmo nome, e um espaço de fórum em que usuárias podem trocar informações variadas sobre fertilidade, gestação e criação de filhos, acessivel tanto via site como via app. 
- Construção do corpo grávido, do "bebê" e da gestação

Através do uso dos aplicativos o processo de gestação vai sendo produzido e reafirmado, semana por semana. Ao abrir os apps, a primeira informação que aparece é em qual semana a gravidez se encontra, $e$ as informações são oferecidas sempre de forma específica ao período gestacional em questão. Ao clicar na imagem do feto, ela é ampliada e mostra-se detalhes de seu desenvolvimento, como o peso e tamanho médio esperado, que vão se modificando semana a semana. Informações mais detalhadas sobre o feto aparecem na seção "meu bebê". Há também uma representação da barriga grávida e do feto visível dentro dela, que vai crescendo com o avanço da gestação.

Figura 9: Imagem da interface inicial do app Gravidez+ com 14 semanas de gestação (esquerda), da seção "meu bebê" (meio) e da simulação do corpo da gestante e a posição/tamanho do feto (direita)
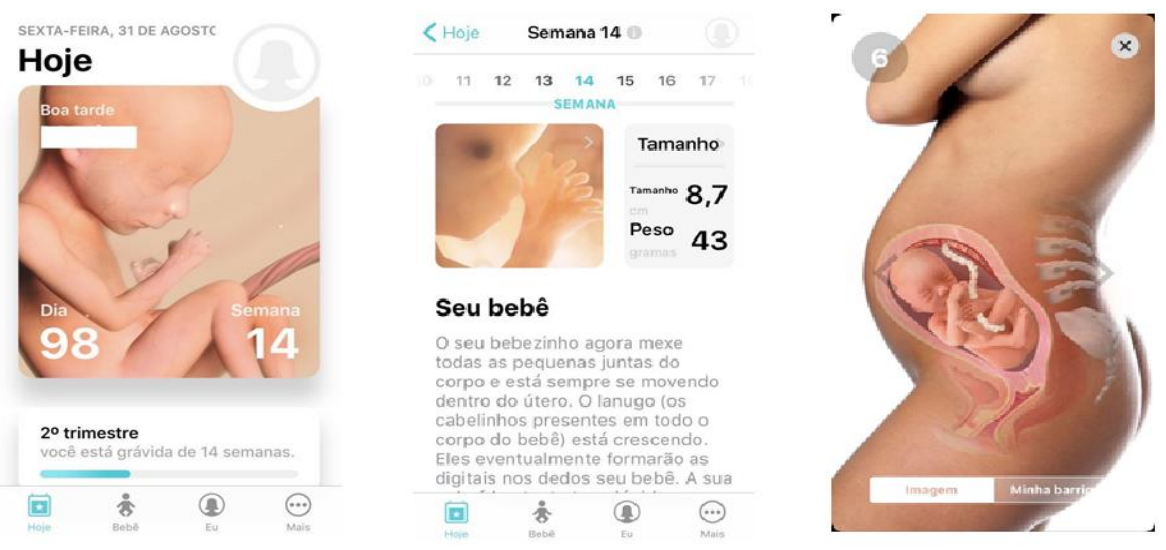

O aplicativo BabyCenter também se atualiza semanalmente com informações sobre o estágio da gravidez $e$ do desenvolvimento do feto. Além dessas informações estarem disponíveis no próprio app, há também a opção de recebê-las 
diretamente por email. A imagem inicial do BabyCenter exibe uma espécie de gráfico que indica o estágio da gravidez, além de uma fruta ou legume que será comparada ao tamanho médio de um feto em cada semana de gestação.

Figura 10: Imagem da interface inicial do app BabyCenter com 15 semanas de gestação

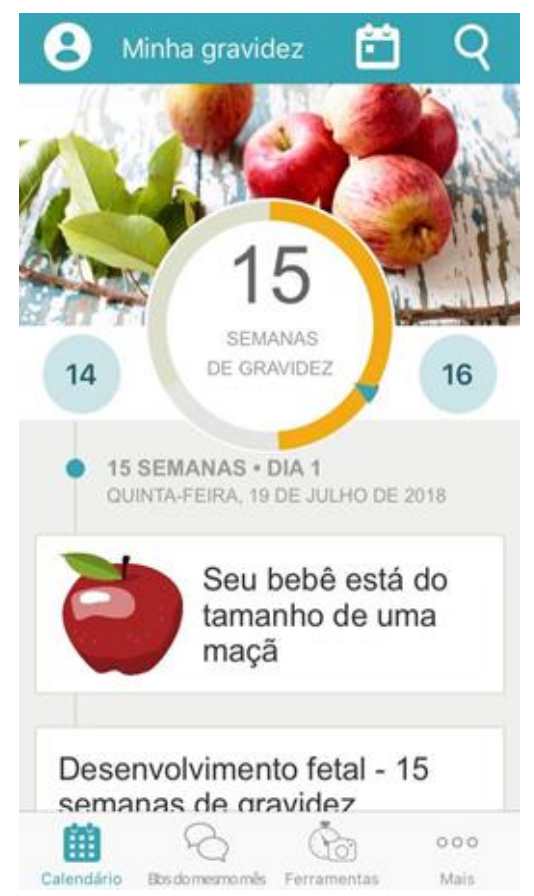

A terminologia médica, que organiza a gravidez em semanas, parece estar se espalhando para a forma como muitas gestantes se referem corriqueiramente à própria gravidez, somando-se, ou mesmo substituindo, a contagem tradicional da gravidez por meses (Tiidenberg; Baym, 2017). Assim, os próprios aplicativos, ao utilizarem a contagem por semana, ao mesmo tempo em que apontam para esta mudança, colaboram para seu reforço. 
Outro aspecto em comum aos dois aplicativos é o incentivo de que as mulheres fotografem suas próprias barrigas $e$ acompanhem seu crescimento. Há seções específicas para se criar um álbum com fotos da barriga semana a semana, além de um banco de imagens de outras gestantes para fins de comparação. Nota-se, portanto, uma valorização intensa da experiência corporal da gestação e do corpo da gestante, em especial da aparência da barriga, que se articula à valorização da exposição pública desses corpos. Neste mesmo sentido, como observa Eliane Vargas (2012), se na década de 1950 a "moda gestante" eram as batas que escondiam a gravidez, na atualidade o "barrigão" deve estar sempre à mostra ou, quando coberto pela roupa, este deve ser marcado e não escondido. Assim, como podemos ver, os aplicativos incentivam e facilitam o registro do "barrigão".

\section{- Automonitoramento e Gestão das Informações}

Ambos os aplicativos possuem extensos termos de privacidade e de uso, localizados de forma "labiríntica", através de links que se remetem por sua vez a outros links, e que exigem grande esforço da usuária para ler e entender todos os termos. No Gravidez+ há informações sobre o recolhimento de dados pessoais, obrigatórios para o uso do aplicativo, e que podem ser repassados para outras empresas afiliadas, bem como empresas fornecedoras de serviços externos.

Já no BabyCenter, a usuária é responsável por todo conteúdo postado, e ao mesmo tempo concede o direito ao BabyCenter e suas afiliadas em relação a este conteúdo. Neste app, além de constar a política de privacidade atual, há o aviso de que ela poderá ser alterada a qualquer momento, e que a continuação do uso após a publicação da nova política no site já caracteriza a aceitação das mudanças. Assim, a usuária é responsável por visitar periodicamente o site do BabyCenter e checar se houve alguma alteração na política. Em caso de discordância, a usuária deve deixar de utilizá-lo. 
Outro ponto importante a ser observado nos termos de uso diz respeito à finalidade do aplicativo e da exatidão das informações de cunho médico. Nos termos de uso do Gravidez+ há o aviso de que ele não deve ser utilizado como substituição de orientações do médico ou de outros profissionais de saúde, e se destina apenas para fins educacionais. Consta nos termos de uso do app que ele não oferece garantia quanto à exatidão das informações fornecidas. Esta informação também aparece de tempos em tempos durante a navegação no app, como na imagem abaixo:

Figura 11: Mensagem de aviso do app Gravidez +

MENSAGEM IMPORTANTE

\section{Aviso}

Por favor, observe que este app

não é um instrumento médico. Não

temos qualquer controle sobre

como você usa o app.

Você é o único responsável pela correção e completude de suas anotações, e a maneira que você usa o seu app pode levar a leituras imprecisas - por favor, revise com cuidado nosso guia sobre como usar o app.

Por favor, garanta que você nunca dependerá exclusivamente do app, por exemplo, para o registro de chutes, contrações, consultas e peso, e que irá buscar apoio em um médico de sua confiança. 
A mesma ressalva é feita enfaticamente nos termos de uso do BabyCenter, em letras maiúsculas:

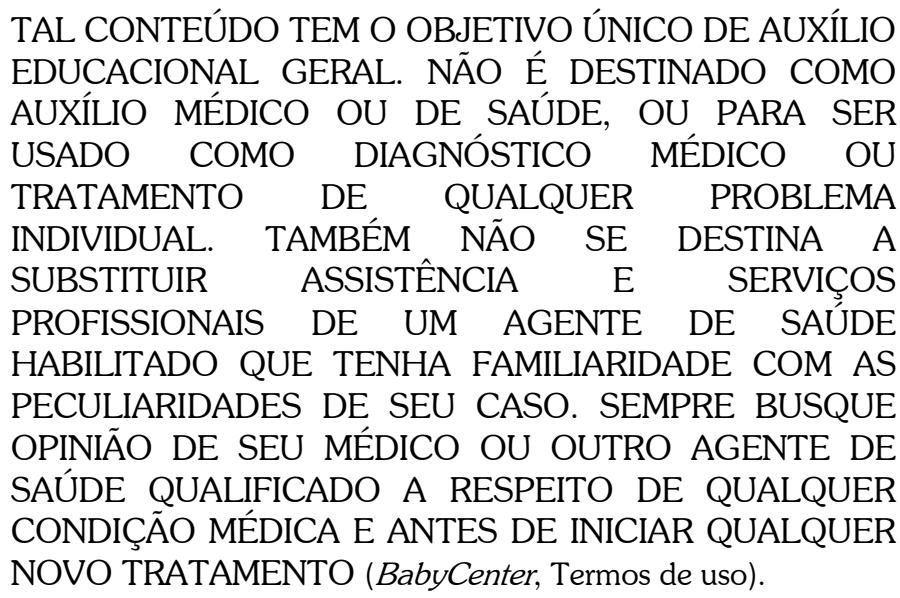

De forma similar, em análise de diversos aplicativos sobre saúde, Lupton e Jutel (2015) verificaram a presença de avisos legais que enfatizavam o uso para fins de "entretenimento" $e$ "educação". Mesmo naqueles aplicativos cujas propagandas alardeavam a possibilidade de que o usuário diagnostique, através do app, algum problema de saúde, acrescentava-se, em seus termos de uso, a ressalva legal de que o app não substituiria orientação médica e não seria destinado para fins diagnósticos, devendo a usuária procurar um profissional médico.

Uma dimensão que chama atenção no conteúdo dos aplicativos para gestantes é a vigilância e normatividade dos corpos grávidos. Em ambos os aplicativos há diversos textos voltados para discutir a segurança, e prescrição ou interdição de certos hábitos e práticas durante a gravidez. Os textos vão desde a recomendação de que não se consuma álcool ou cigarros neste período, até questões como "grávidas podem fazer radiografia?", "grávida pode pintar paredes ou ficar perto do cheiro de tinta?", "grávida pode fazer regime?", "grávida pode usar salto alto?", "grávida pode comer chocolate?”. 
Nem sempre as respostas a essas perguntas são proibições. No caso do chocolate, por exemplo, o texto do aplicativo Babycenter diz:

\begin{abstract}
Boa notícia: grávida pode comer chocolate! Os especialistas dizem que a quantidade de cafeína presente no chocolate é pequena e, mesmo assim, não há nada que comprove que o consumo moderado de alimentos que contenham cafeína possa ser prejudicial às gestantes ou aos bebês (BabyCenter, grifos do original).
\end{abstract}

Mesmo que não haja uma proibição no caso do chocolate, aparece, no texto acima, a ideia de que a gestante deve, a priori, consultar especialistas (ou o aplicativo, que aqui faz um papel de porta-voz) para se informar acerca da segurança do que ela faz ou consome. Isto é, trata-se da noção de que a gravidez é um momento em que todos os hábitos deverão ser revistos para que não sejam prejudiciais "às gestantes ou aos bebês". Assim, sendo a gravidez um período de perigo, cercado de riscos, a autovigilância da gestante deverá ser guiada pelos saberes médicos e prescrições de especialistas (Lupton, 1999).

Neste mesmo sentido, é bem marcada, nos aplicativos, a ideia de que a gravidez é um momento em que a mulher deve redobrar os cuidados consigo mesma. Estes vão desde procedimentos médicos específicos (como exames e consultas de pré-natal), até cuidados que ficam em uma fronteira fluida entre saúde e estética, como o controle sobre o ganho do peso $e$ cuidados com a pele.

No que diz respeito ao âmbito médico, os aplicativos oferecem desde ferramentas para organizar a agenda de exames e consultas, a textos informativos sobre a importância do pré-natal e de exames próprios a cada idade gestacional. Essas informações variam de acordo com cada período da gravidez. No início da gravidez, por exemplo, o app Gravidez+ apresenta um texto chamado "Exames do primeiro trimestre". Ao longo do texto há uma lista de exames normalmente feitos no primeiro trimestre, com a seguinte introdução: "Durante o primeiro trimestre da sua 
primeira gravidez, você pode se sentir como uma alfineteira humana, pois seu médico realizará diversos exames para verificar se você e seu bebê estão saudáveis" (grifos nossos).

Cabe ressaltar, porém, que a listagem de exames apresentada se refere ao contexto estadunidense, $e$ não necessariamente coincide com aqueles comumente solicitados em pré-natal no Brasil, como rastreio para alterações genéticas, por exemplo. Isto indica, como já falamos anteriormente, que, embora o conteúdo em inglês seja traduzido para o português, não há uma devida adaptação para o contexto local. Entretanto, para além dos exames específicos em cada contexto, a noção de que uma gestante é uma espécie de "alfineteira humana", que deverá ser "furada" diversas vezes para realizar exames de sangue, faz parte da lógica de uma gravidez hiper-medicalizada também no Brasil, em especial no contexto das camadas médias urbanas (Nakano; Bonan; Teixeira, 2015).

Nos aplicativos, os exames de ultrassom ganham destaque tanto do ponto de vista diagnóstico (como ferramenta para detecção da viabilidade ou não de gestações ainda no seu começo, ou rastreio de malformações) como na construção de uma subjetividade do feto e do "prazer de ver o bebê" (Chazan, 2007). 
Figura 12: Imagem da interface do app BabyCenter com uma fotografia de feto em 3D

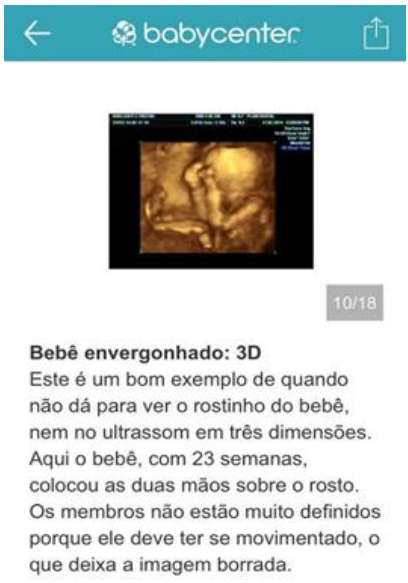

Como observa Chazan (2007), as imagens fetais obtidas através do ultrassom passam a ser naturalizadas e equiparadas a "fotos", compondo o álbum de fotografias como o primeiro registro "do bebê". Embora tecnicamente não sejam fotografias, o uso deste termo é corriqueiro, e contém de forma implícita a ideia do feto "externalizado" através do ultrassom. Embora o ultrassom fetal originalmente seja utilizado com objetivos médicos, a dimensão de consumo e lazer estão bastante presentes em sua prática, questão que permeia também o modo como o ultrassom é tratado nos aplicativos.

Outro ponto que aparece com destaque em ambos os apps é a necessidade de controle do ganho de peso durante a gestação. No Gravidez+ há uma ferramenta em que é possível registrar o peso da gestante mês a mês, enquanto o aplicativo gera um gráfico indicando a variação de peso. Já no BabyCenter, há diversos textos sobre mudanças do corpo durante a gravidez, com ênfase para o ganho de peso esperado neste período, mas também com dicas para que este aumento não seja demasiado, como a recomendação de exercícios regulares moderados $e$ alimentação balanceada. 
Além disso, o aplicativo oferece também uma calculadora para ganho de peso: informando-se dados como peso antes de engravidar e altura, ele faz um cálculo estimativo de quantos quilos idealmente a gestante irá engordar. Juntamente com o resultado, aparece, porém, o seguinte aviso: "IMPORTANTE: A calculadora do ganho de peso na gravidez é uma ferramenta educativa que tem os dados baseados em estatísticas norteamericanas. Ela não deve substituir as orientações transmitidas a você pelo médico durante o pré-natal". $\mathrm{O}$ aviso, portanto, corrobora com o que tratamos acima, a respeito das ressalvas legais no uso dos aplicativos.

\section{- Variações hormonais e amor materno: sentidos de gênero nos aplicativos}

Ideais acerca da feminilidade e maternidade permeiam todo conteúdo do aplicativo. A gestação aparece como um momento que modifica o corpo das mulheres, mas também afeta aspectos emocionais e mentais. A explicação para tais mudanças evoca a ideia da mulher como sendo governada por seus hormônios, $e$ constitui o que Fabíola Rohden (2008) irá chamar do império de um corpo hormonal, isto é, a hegemonia dos hormônios como chave explicativa sobre o funcionamento de corpos e emoções.

De acordo com o app BabyCenter, durante a gravidez as mulheres seriam "inundadas" com hormônios, e esses hormônios ditariam e controlariam o humor da mesma forma que uma "TPM gigante", como ilustrado no trecho abaixo:

Você se sente ótima em um minuto e no outro está em prantos? Bem-vinda ao clube! As variações radicais de humor e estado de espírito são bastante comuns durante a gravidez. [...] Os especialistas acreditam que a progesterona $e$ o estrogênio sejam parcialmente responsáveis por isso, mais ou menos como uma TPM gigante.[...] A consciência de que você está se comportando conforme o esperado (e conforme ditam seus hormônios) 
talvez sirva para aliviar um pouco da culpa por tantos altos e baixos (BabyCenter, grifos nossos).

A explicação hormonal também é evocada para tratar do amor entre pais e filhos, mas, especialmente, do amor materno. Se Elizabeth Badinter (1985) já se dedicou a localizar historicamente a conformação do que irá chamar de "mito do amor materno", no texto "A ciência explica como brota seu amor pela criança", disponível no app BabyCenter, tal amor permanece sendo reafirmado como de ordem biológica, e não cultural.

O elo que existe entre pais e filhos é uma das ligações mais fortes da natureza. [...] o amor por uma criança não é intelectual ou cultural - ele é sim um componente básico da formação de todos os seres humanos. [...]

Os hormônios que circulam no corpo de uma mulher grávida (e que ficam mais potentes a cada semana de gestação) também ajudam a alimentar a conexão com o bebê. À medida que a data do parto se aproxima, o cérebro começa a produzir cada vez mais oxitocina, um hormônio que auxilia a trazer à tona a "mãe" que está dentro de você. Também conhecida como o hormônio do amor, a oxitocina é responsável pelo comportamento maternal em animais. Resumindo: quando a oxitocina circula pelo corpo de uma gestante é como se o amor estivesse correndo por suas veias (BabyCenter).

Como observam Rohden e Alzuguir (2016), a ocitocina apelidada de "hormônio do amor" - tem aparecido cada vez mais como protagonista neste império do corpo hormonal. Podemos encará-la aqui como uma espécie de tentativa de tradução neuroquímica do amor materno, que se evidencia principalmente na frase do trecho acima: "quando a oxitocina circula pelo corpo de uma gestante é como se o amor estivesse correndo por suas veias". Dentro desta lógica, à medida que as semanas da gravidez avançam, cresce a barriga, o feto, mas também os níveis de ocitocina e, consequentemente, os "níveis" de amor materno. 
Por fim, concordamos com a análise de Thomas e Lupton (2015) de que os aplicativos para gravidez valorizam uma autovigilância e que, mais do que nunca, as gestantes e fetos tornam-se altamente visíveis, estetizados e monitorados, tanto para fins médicos quanto para entretenimento e consumo.

Ao contrário dos apps para controle do ciclo menstrual, que dependem das informações fornecidas mensalmente por suas usuárias para calcular o período fértil e oferecer informações específicas sobre o ciclo de cada uma, os apps de gravidez não necessitam do fornecimento constante de informações das usuárias. Como vimos, apenas a data da última menstruação é solicitada, e a partir daí o app calcula a data provável para o parto e estima o estágio em que a gestação se encontra. Não há, portanto, um retorno ou atualização das informações que sejam específicas para cada gestante. Toda gestante recebe conteúdos similares, partindo-se do princípio de que o desenrolar de uma gravidez e o desenvolvimento fetal será parecido para todas as mulheres.

Mas há vezes em que a gravidez não segue este "script", como em casos de perdas fetais. Ao tentar se descadastrar do aplicativo BabyCenter, há um link que redireciona a usuária para uma seção sobre abortos espontâneos, indicando que este seria um dos motivos mais frequentes a levar usuárias a deixarem de utilizar o app. Na seção, além de links para textos sobre o assunto, há uma explicação sobre como cancelar os boletins daquela gestação, para evitar "notificações dolorosas":

Para cancelar os boletins, clique aqui para entrar nas informações da sua família e selecione "retirar da minha conta". É rápido. Se você é usuário ou usuária do aplicativo BabyCenter, precisa fazer esse processo para fazer 0 descadastramento. Apenas apagar o aplicativo não elimina seus dados do sistema. Caso não queira apagar o aplicativo, para continuar usando a comunidade, por exemplo, por favor faça o login pelo menos uma vez depois de atualizar seus dados para não receber notificações que sejam dolorosas. Se encontrar alguma dificuldade, por 
favor nos escreva pelo email br_faleconosco@babycenter.com, pois poderemos ajudá-la. Sentimos muito pelo que aconteceu (Babycenter).

\section{Aplicativos, Informações, Governamentalidades}

Fertilidade e reprodução são a base da reprodução humana, e social, fontes primordiais da incisão das biopolíticas de populações, e da gestão e organização das tecnologias de gênero que constroem corpos femininos $e$ masculinos $e$ suas (in)fertilidades. Os aplicativos aqui descritos atualizam discussões das perspectivas feministas sobre corpo, saúde e gênero, e suas relações com tecnologias. Contribuem para reforçar e reificar noções essencializantes sobre os corpos femininos como cíclicos, instáveis, destinados à gestação (que deve ser programada $e$ observada). Corpos que precisam ser monitorados e controlados em suas funções férteis e reprodutivas.

Com suas interfaces convidativas, os aplicativos de ciclo menstrual e gravidez seduzem usuárias para um exercício compartilhado desse monitoramento. Fornecem às usuárias uma concentração informacional de dados sobre sua saúde $e$ fertilidade, sobre seu funcionamento corporal, seus hábitos, sentimentos, humores, sua vida sexual, sobre como deve estar seu bebê. Tudo isso em troca da sua circulação nos respectivos bancos de dados das empresas que os criaram.

Ao fazê-lo, essas tecnologias configuram um certo tipo de abordagem para compreender e experimentar o corpo, uma subjetividade algorítmica (Lupton, 2016), em que o corpo e seus estados de saúde, funções e atividades são quantificados, previstos e/ou comparados. Elas trabalham para externalizar a sexualidade $e$ as capacidades reprodutivas, transformando-as em dados digitais visíveis e compartilháveis. Quantificadas e digitalizadas, as experiências atreladas à gravidez e ao ciclo menstrual, em suas múltiplas complexidades, aparecem de forma reduzida, codificada e comparativa, já que submetidas a categorias coletivas $e$ previamente definidas. 
As informações sobre ciclo menstrual e gravidez, produzidas por mulheres $e$ seus aplicativos compõem um arranjo múltiplo $e$ complexo de informações preciosas a respeito de como corpos femininos funcionam, e como corpos humanos são gerados. Direcionar esses arranjos no sentido da autonomia, do conhecimento e da liberdade das usuárias segue, ainda, um desafio diante do horizonte mais provável, no qual esses dados servem, antes, para alimentar e informar novas, e velhas, formas de controle e dominação.

\section{Referências bibliográficas}

BADINTER, Elisabeth. Um amor conquistado: o mito do amor materno. Rio de Janeiro: Nova Fronteira, 1985.

BARASSI, Veronica. BabyVeillance? Expecting Parents, Online Surveillance and the Cultural Specificity of Pregnancy Apps. Social Media + Society, v. 3, n. 2. 2017, pp.1-10. https://doi.org/10.1177/2056305117707188 Último acesso em 26/10/2020.

BOULOS, Maged et al. Mobile medical and health apps: state of the art, concerns, regulatory control and certification. Online Journal of Public Health Informatics, v. 5, n. 3, 2014, pp.1-23. https://doi.org/10.1371/journal.pone.0211551 Último acesso em 26/10/2020.

CHAZAN, Lilian. "Meio Quilo de Gente": um estudo antropológico sobre ultra-som obstétrico. Rio de Janeiro: Editora Fiocruz, 2007.

ELIAS, Ana; GILL, Rosalind. Beauty surveillance: The digital selfmonitoring cultures of neoliberalism. European Journal of Cultural Studies, v. 21, n. 1, 2017, pp.1-19. https://doi.org/10.1177/1367549417705604 Último acesso em 26/10/2020.

FELIZE, Natasha; VARON, Joana. s/d. Menstruapps: Como transformar sua menstruação em dinheiro. Disponível em: https://chupadados.codingrights.org/menstruapps-comotransformarsua-menstruacao-em-dinheiro-para-os-outros/ Último acesso em 23/04/2019. 
FOUCAULT, Michel. História da sexualidade: a vontade de saber (vol 1). Rio de Janeiro: Edições Graal, 1988 [1976].

GRAY, Miranda. Lua Vermelha: as energias criativas do ciclo menstrual como fonte de empoderamento sexual, espiritual e emocional. São Paulo: Editora Pensamento, 2017.

HARAWAY, Donna. Manifesto ciborgue: ciência, tecnologia e feminismo-socialista no final do século XX. In: HARAWAY, Donna et al. Antropologia do ciborgue: as vertigens do pós-humano. Belo Horizonte: Autêntica, 2009 [1985].

KANASHIRO, Marta Mourão. Biometria no Brasil e o Registro de Identidade Civil: novos rumos para identificação. Tese (Doutorado em Sociologia). Universidade de São Paulo, 2011.

KNIGHT, Jane. The Complete Guide to Fertility Awareness. Londres: Routledge, 2016

KLÖPPEL, Bruna. Aparatos de Produção Subjetivo-Corporais nas Práticas de Percepção da Fertilidade. 2017. 158 f. Dissertação (Mestrado em Antropologia Social). Universidade Federal do Rio Grande do Sul, Porto Alegre. 2017.

LISTER C, WEST JH, CANNON B, SAX T, BRODEGARD D. Just a fad? Gamification in health and fitness apps. JMIR Serious Games. 2014;2(2):e9. Published 2014 Aug 4. doi:10.2196/games.3413 Último acesso em 26/10/2020.

LUPTON, Deborah. Risk and the ontology of pregnant embodiment. In: . Risk and Sociocultural Theory: New Directions and Perspectives. Cambridge: Cambridge University Press, 1999, pp.5985.

. Beyond Techno-Utopia: Critical Approaches to Digital Health Technologies. Societies, v.4, 2014, pp.706-711. https://doi.org/10.3390/soc4040706 Último acesso em 26/10/2020.

. Quantified sex: a critical analysis of sexual and reproductive self-tracking using apps. Culture, Health \& Sexuality: An International Journal for Research, Intervention and Care, abril, 2015. https://doi.org/10.1080/13691058.2014.920528 Último acesso em 26/10/2020.

. The quantified self. Malden: Polity, 2016. 
Toward a More-Than-Human Analysis of Digital Health: Inspirations From Feminist New Materialism. Qualitative Health Research. 2019. https://doi.org/10.1177/1049732319833368 Último acesso em 26/10/2020.

LUPTON, Deborah; JUTEL, Annemarie. 'It's like having a physician in your pocket!' A critical analysis of self diagnosis smartphone apps. Social Science \& Medicine, v. 133, 2015, pp.128-135. https://doi.org/10.1016/j.socscimed.2015.04.004 Último acesso em 26/10/2020.

MOGLIA, Michelle et al. Evaluation of smartphone menstrual cycle tracking applications using and adapted APPLICATIONS scoring system. Obstetrics and Gynecology, v. 127, n. 6, 2016, pp.11531160. doi: 10.1097/AOG.0000000000001444 Último acesso em 26/10/2020.

MOL, Annemarie. The body multiple: ontology in medical practice. Duhhann e Londres, Duke University Press, 2002.

NAKANO, Andreza; BONAN, Claudia; TEIXEIRA, Luiz. A normalização da cesárea como modo de nascer: cultura material do parto em maternidades privadas no Sudeste do Brasil. Physis, n. 25, v. 3, 2015, pp.885-904. https://doi.org/10.1590/S010373312015000300011. Último acesso em 26/10/2020.

PALETTA, Gabriela Cabral. Menstruapps na era farmacopornográfica: aplicativos de monitoramento de ciclo menstrual e interseções entre corpos, máquinas e tecnopolíticas de gênero. Dissertação (Mestrado em Sociologia e Antropologia. Rio de Janeiro: UFRJ, 2019.

PARRA, Henrique. Experiências com tecnoativistas: resistências na política do dividual? In: BRUNO, Fernanda et al (orgs.). Tecnopoliticas da Vigilância: perspectivas da margem. São Paulo: Boitempo, 2018, pp.341-354.

PRECIADO, Beatriz. Manifesto contrassexual. São Paulo: n-1 edições, 2014.

PRECIADO, Paul. Testo Junkie: Sexo, drogas e biopolítica na era farmacopornográfica. São Paulo: n-1 edições, 2018.

RIBEIRO, Stephanie. Sua menstruação vale ouro mas você não está ficando mais rica por isso. 2017. Modefica. Disponível em: 
https://www.modefica.com.br/aplicativos-menstruacaodados/\#.XUdLo5NKgUt. Último acesso em 05/08/2019.

ROHDEN, Fabíola. Império dos hormônios e a construção da diferença entre os sexos. História, Ciência, Saúde - Manguinhos, v. 15, supl., 2008, pp.133-152.

ROHDEN, Fabíola; ALZUGUIR, Fernanda. Desvendando sexos, produzindo gêneros e medicamentos: a promoção das descobertas científicas em torno da ocitocina. Cadernos Pagu [online]. 2016, n.48, e164802.

SACRAMENTO, Igor; WANICK, Vanissa. mHealth and the Digital Cyborg Body: The Running Apps in a Society of Control. In: MARSTON, Hannah; FREEMAN, Shannon; MUSSELWHITE, Charles. Mobile e-Health, Springer, 2017, pp.39-70.

SANDERS, Rachel. Self-tracking in the Digital Era: Biopower, Patriarchy, and the New Biometric Body Projects. Body \& Society, v. 3, n. 1, 2016, pp.36-63.

THOMAS, Gareth; LUPTON, Deborah. Threats and thrills: pregnancy apps, risk and consumption. Health, Risk \& Society, v. 17, n. 7-8, 2015, pp. 1-1.

TIIDENBERG, Katrin; BAYM, Nancy. Learn It, Buy It, Work It: Intensive Pregnancy on Instagram. Social Media + Society, January-March, 2017, pp.1-13.

VAN DJICK, José; POELL, Thomas. Understanding the promises and premises of online health platforms. Big Data \& Society, v. 3, n. 1, 2016, pp.1-11.

VARGAS, Eliane Portes. 'Barrigão à mostra': vicissitudes e valorização do corpo reprodutivo na construção das imagens da gravidez. História, Ciências, Saúde - Manguinhos, v. 19, n. 1, 2012, pp.237258. 